\title{
Erratum
}

\section{Spontaneous Symmetry-Breaking Energy Functions and the Emergence of Orientation Selective Cortical Cells}

D. M. Kammen and A. L. Yuille

Biol. Cybern. 59, 23-31 (1988)

The Note Added in Proof in Kammen and Yuille (1988) [1] should be deleted. After clarification by the author [2] we see that the model of orientation selectivity proposed by Linsker [3] (1986) generates orientation selective cortical cells without the use of an asymmetric correlation function.

\section{References}

1. Kammen DM, Yuille AL (1988) Bio Cybern 59:23-31

2. Linsker R (1988) Private communication

3. Linsker R (1986) Proc Natl Acad Sci USA 83:7508-7512, $8390-8394,8779-8783$

Verantwortlich für den Textteil: Prof. Dr. W. Reichardt. Max-Planck-Institut für biologische Kybernetik, Spemannstr. 38, D-7400 Tübingen. Verantwortlich für den Anzeigenteil: E. Lückermann, Springer-Verlag, Heidelberger Platz 3, D-1000 Berlin 33, Fernsprecher: (030)8207-0, Telex: 185411. (C) Springer-Verlag Berlin Heidelberg 1988. Druck der Brühlschen Universitätsdruckerei, Gießen. Printed in Germany. - Springer-Verlag GmbH \& Co KG, 1000 Berlin 33 